\title{
COLOMBIANOS E COLOMBIANAS: UM POVO QUE NÃO SE CALA DIANTE DOS IMPERATIVOS DESTRUIDORES DO NEOLIBERALISMO Entrevista com a Professora Dra. Beatriz Nates Cruz
}

\author{
COLOMBIANOS Y COLOMBIANAS: UN PUEBLO QUE NO SE CALLA ANTE LOS \\ IMPERATIVOS DESTRUCTIVOS DEL NEOLIBERALISMO \\ Entrevista a la Profesora Dra. Beatriz Nates Cruz
}

Cláudio Jorge Moura de Castilho1

Entrevista recebida em 12/07/2021, aceita em 21/07/2021, publicada em 22/07/2021.

\begin{abstract}
Palavras-chave:
Lutas sociais;

protestos;

especificidades

territoriais e

históricas;

Colômbia;

Equidade temporal;

Valorização dos

povos

"invisibilizados".

Entrevista realizada pelo Prof. Cláudio Jorge Moura de Castilho, do grupo de pesquisa Movimentos Sociais e Espaço Urbano (MSEU), com a Profa. Dra. Beatriz Nates Cruz, da Universidad de Caldas (UCALDAS), em Manizales, Colômbia. Esta entrevista teve como finalidade principal a de esclarecer as razões fundamentais e a natureza político-filosófica dos atuais protestos desencadeados no seu país, o que se faz importante para o acompanhamento de uma problemática que, na verdade, acha-se vinculada à América Latina como um todo. Os procedimentos metodológicos à realização desta entrevista basearam-se, primeiramente, no envio de um formulário com as questões elaboradas pelo MSEU a fim de que a Profa. Béatriz as respondesse livremente, inclusive fazendo os acréscimos e sugestões necessários; e, em seguida, o formulário foi-nos remetido pela Professora, tendo sido publicado na sua íntegra, respeitando, assim, o conteúdo de uma fala de uma Professora-Cidadã da Colômbia.
\end{abstract}

Keywords:

Luchas sociales;

protestas;

características

territoriales e

históricas;

Colombia; Equidad

temporal;

Valoración de los

pueblos

"invisibilizados".

\section{RESUMO}

\section{RESUMEN}

Entrevista realizada por el Prof. Cláudio Jorge Moura de Castilho, del grupo de investigación Movimientos Sociales y Espacio Urbano (MSEU), con la Profa. Dra. Béatriz Nates Cruz, de la Universidad de Caldas (UCALDAS), en Manizales, Colombia. El objetivo principal de esta entrevista fue esclarecer las razones fundamentales y el carácter político-filosófico de las actuales protestas desatadas en su país, lo cual es importante para dar seguimiento a un problema que, de hecho, está ligado a América Latina en su totalidad. Los procedimientos metodológicos para la realización de esta entrevista se basaron, en primer lugar, en el envío de un formulario con las preguntas elaboradas por el MSEU para que la Profa. Beatriz les respondiese libremente, incluyendo las adiciones y sugerencias necesarias; y luego el formulario nos lo envió la Profesora, habiendo sido publicado en su totalidad, respetando así el contenido de un discurso de una Profesora-Ciudadana de Colombia.

\footnotetext{
1 Professor do Programa de Pós-graduação em Desenvolvimento e Meio Ambiente da Universidade Federal de Pernambuco (PRODEMA/UFPE) e coordenador do Grupo de Pesquisa Movimentos Sociais e Espaço Urbano da Universidade Federal de Pernambuco (MSEU/UFPE).
} 
Movimentos Sociais e Espaço Urbano (MSEU): Aquí en Brasil, por un lado, la prensa comercial ha estado en los titulares sobre las actuales protestas desatadas por el pueblo colombiano de manera lacónica y rápida; $y$, por otro lado, los medios alternativos han destacado tales desarrollos como meras reacciones al neoliberalismo. Estas visiones simplistas nos impiden comprender la realidad social como una totalidad. Total, ¿qué está pasando realmente en Colombia?

Respuesta: Colombia es un país que se ha creado en medio de conflictivas definiciones territoriales. Y su historia reciente ha estado marcada por demandas de justicia territorial (socioeconómica y política) en particular desde los años 60 del siglo XX. Dos Constituciones Políticas han marcado la vida de este país: La de 1886 y la de 1991. Durante las décadas de 1970 a 1990, tuvo lugar una insurrección guerrillera fuerte. Varias surgieron EPL, PRT, M-19, ELEN y FACR-EP. Todas producidas como una demanda armada frente a la imposibilidad de justicia básica para la vida rural y urbana en Colombia. Por ello, la esperanza se puso en la Constitución de 1991, esperando así, que se diera la democracia que tanto se anhelaba, pero pasados los años, todo no sólo no se resolvió a favor del pueblo, sino que se dio una concentración de poder violento y absolutista. De los 30 años de esta Constitución (1991-2021), 20 han estado en las manos de Álvaro Uribe Vélez, quien ha arrastrado a todo el país con su odio personal por la muerte de su padre, según él en manos de la guerrilla FARC-EP. Por tanto, un odio personal, nos tiene hoy en 2021, reducidos a un capitalismo criollo que se revuelca en odios domésticos y lo eleva a la expresión del gobierno nacional y sus instituciones. Actualmente su partido el mal llamado Centro Democrático ha acaparado todos los poderes: presidencia, fiscalía, procuraduría + los poderes ministeriales todos en sus manos. Pareciera una caricatura, pero es la vida personal de un hombre (secundado por los ricos que aprovechan de este odio y él también) que domina y pone odios y perdones o castigos donde quiere y entre tanto, el país se empobrece, los muertos no cesan. Con el gobierno de Juan Manuel Santos durante esos 20 años de poder de Uribe, se produjo una demarcación durante 8 años para firmar el Acuerdo de Paz con las hoy ex FARC-EP. Y dada la soberbia de este hoy Premio Nobel, Juan Manuel Santos, se llevó a un Plebiscito la aprobación del Acuerdo de Paz, donde ganó el NO. Acto que fue aprovechado por Uribe para sumirnos en unos odios más extendidos con aumento de lo que creíamos diezmado, el paramilitarismo en campo y ciudad. Hoy en 2021, lo que pasa es un reclamo por una justicia de larga duración, por el respeto a la vida digna, por una democracia vivida.

MSEU: Ante lo que acaba de decir, ¿vale la pena reiterar lo que, de hecho, está llevando a colombianos y colombianas a ocupar actualmente espacios públicos en Colombia para realizar sus protestas. ¿Será que esto solo se debe a la propuesta de reforma tributaria del actual gobierno colombiano, como se ha dicho repetidamente aquí en Brasil? 
Respuesta: Justamente lo que acabo de decir deja claro que la explosión dada en la calle por la Reforma Tributaria fue la copa que rebosó el vaso, no la causa. Fue un arrinconamiento social muy perverso. Hemos vivido una pandemia con una de las cuarentenas más largas de América Latina, nos encerraron en marzo de 2020 y sólo en octubre nos permitieron movernos. Con toda la pobreza económica, con toda la crispación social y humana, cómo es posible que un gobierno pretenda comprarse lujos como lo hizo Duque: carros blindados de costos enormes, aviones de guerra, viajes de su fiscal de vacaciones en medio de la cuarentena, etc. Y el pueblo muriendo de hambre de forma literal. Nuestros estudiantes en las universidades públicas debieron cancelar sus carreras porque no tenían una computadora, no tenían acceso a internet, no tenían sustento. Los ricos más ricos y los pobres más pobres: esa es la clave para buscar salvadores y allí Uribe Vélez y su partido lo saben hacer bien, para continuar con el poder político y económico.

MSEU: ¿En qué medida podría considerarse la reacción de los colombianos y de las colombianas ante el referido intento de reforma tributaria como el detonante para desencadenar otras demandas sociales en el contexto histórico de un tema mucho más complejo - referido a la profundización de los imperativos inherentes a la reanudación de acciones apoyadas por Razón neoliberal - en Colombia, como también ha ocurrido en otros países latinoamericanos?

Respuesta: El neoliberalismo a secas, por sí sólo no es el problema. Cada país tiene una historia y la nuestra como la he resumido en el punto uno [na primeira resposta] de esta entrevista, es la demanda básica por una Carta Constitucional que nos represente y llevamos 30 años sin que eso suceda (Constitución de 1991). Allí y para tocar el tema de esta pregunta, podemos precisar lo que ha acontecido con la concentración de la tierra y el uso del suelo. A menudo digo que en Colombia la disyunción entre gente con tierra y sin territorio y de gente con territorio y sin tierra, es cada vez más pronunciado en este país. Por ello, quiero decir que los desposeídos aumentan con las décadas y los dueños de la tierra cada vez no viven en el país o poco les importa el país como tal. Tienen tierra y les tiene sin cuidado el territorio (la geosociohistoricidad), y los colombianos que nos quedamos que cada día construimos y reconstruimos el país tenemos con alto sentido de pertenencia y la escasa o ausencia de propiedad sobre la tierra (de una casa, una parcela...) es cada vez más pronunciada.

Los reclamos a partir de lo que decantó la fallida reforma tributaria han confluido en forma de todas las demandas represadas, por eso desde afuera hay la impresión que se pide de todo, que no hay representantes claros y que todo parece como si la estrategia misma fuera "atacar" desde la gente que no puede más y salió a la calle con una sola voz. ¿La respuesta del gobierno? guerra en la calle. Tener en cuenta que cuando hay mucho que reclamar y que cuando la gente se siente cada vez más arrinconada, la respuesta es cada vez más contundente. Pero debo hacer una aclaración: los destrozos que fueron publicitados por la prensa internacional deben ser entendidos y de ello hay pruebas (ver ONG Temblores, por ejemplo) por infiltrados que muchos 
señalan como paramilitarismo en la ciudad que hace presencia de todo tipo en las manifestaciones (nosotros lo llamamos paros).

MSEU: Desde el punto de vista más dirigido a la práctica de las acciones de las protestas anteriores, ¿qué territorios - plazas, calles, edificios, etc. - han sido elegidos por los colombianos y las colombianas para su realización? ¿Por qué estos territorios son los más utilizados para sus acciones?)

Respuesta: Sobre esta pregunta de tipo espacial muy pertinente quiero comenzar por referirme a resolver la pregunta de ¿Cómo un espacio se convierte en un concepto político? Lo que quizá habrán escuchado como "La primera Línea" es un buen ejemplo de ello. La primera Línea surgió como una línea literal de jóvenes que se ponían en frente de las protestas para ponerle el pecho a las balas y al maltrato policial y así permitir que el resto de la gente avanzara. Con las semanas los jóvenes de la primera Línea se han convertido en La Primera Línea y han dicho: La primera Línea somos un reclamo, una cualificación del descontento general, somos una posición política que grita que todo está mal, que esto como país, no va a más si seguimos como estamos en Colombia. Eso muestra la versatilidad de cómo se mueve el país, hablamos de semanas y ya tenemos una nueva veta de análisis y de movimiento político-social.

Continuado puedo decir que cuando la guerra era en el campo, el eje espacial (territorial) era lo que llamamos "la vereda" es decir, la mínima expresión territorial rural con a veces un caserío disperso o concentrado, pero que es el emblema del campesinado colombiano. Cuando la guerra se traslada a las calles, a la ciudad se busca los lugares de congregación para la expresión masiva y los barrios para la preparación del movimiento, por eso se dio (se da a aún) al mismo tiempo, la manifestación en plazas, parques, puentes, ejes viales, y entre tanto en los barrios se dan las asambleas comunales. Esto deja ver que el concepto territorio como ensamblaje geosociohistórico es clave para materializar lo que vivimos.

MSEU: ¿Quién se ha involucrado realmente en estas protestas, en términos de clases sociales? ¿Cuáles han sido las principales tácticas y/o estrategias organizativas y de acción utilizadas para llevar a cabo las protestas? ¿Qué apoyo han recibido tales protestas de otros segmentos de la sociedad civil colombiana?

Respuesta: De alguna manera he respondido esto en la anterior pregunta. Me detengo en resumir: los manifestantes han congregado distintas escalas sociales, distintas maneras de pesar, distintas profesiones, 0 poderes adquisitivos. Lo que ha marcado la diferencia con esto es que el uribismo sigue siendo fuerte y así como ha surgido la "primera línea" que he referido antes, surgió algo que denominaron "gente bien". Estos no necesariamente son los de poder económico alto, son sobre todo Opus Dei, algunos jubilados de derechas u otros similares, en los que ha calado ahondo la idea de lo que se llama por aquí entre la ultraderecha "el castrochavismo", es decir el miedo a que nos volvamos Cuba o Venezuela y que se les quite algún bien. Así 
que esta "gente bien" ha homologado el movimiento vivido al mal de la izquierda. Con ello, esta gente y sin hacer diferencia de fondo, se junta en ese rechazo al movimiento social actual y justifican la atrocidad policial y militar, es decir, gubernamental, sobre los indígenas y sobre todos los que hagan liderazgo cualificado del reclamo social.

MSEU: Sabiendo que, en la historia, el Estado ha actuado más como un brazo fuerte de las clases hegemónicas para criminalizar y masacrar cualquier acción contra el orden establecido para garantizar sus privilegios bajo el modo de producción capitalista, ¿hasta qué punto el Estado colombiano está repitiendo más una vez este abominable papel histórico?

Respuesta: Como he dicho antes, la tierra es un factor clave para entender la historia del país y para responder esta pregunta. Aquí hay expresiones de fuerte implicación como "tierras de engorde" y "volteo de tierras". En Colombia el poder político pasa por el poder sobre la tierra. Pero no sólo por una idea de terrateniente, sino por la demanda de reconocimiento extremo de la ultraderecha y el capitalismo criollo. Cuando decimos "tierra de engorde" es cuando los ricos compran tierra sólo para que aumente de precio sin que haya ningún tipo de producción en ella, o simplemente poner en inmensas extensiones de tierra productiva en la zona Andina y de la Costa Atlántica (Caribe) un par de vacas para tener la idea de que se usa. Cuando decimos "volteo de tierra", es cuando se cambia el uso del suelo, y aunque con ello su precio supeditado a las conveniencias. Los planes de ordenamiento territorial son más que un derecho constitucional de 1991, una herramienta que puede sino hay vigilancia del Estado, convertirse en medio de servir a dicho volteo de tierras. En Colombia el caso del Municipio (departamento de Cundinamarca) de Mosquera a favor de los hijos de Álvaro Uribe Vélez es un caso pragmático y en extremo arbitrario del volteo de tierras.

Recomiendo revisar los trabajos de Alejandro Reyes Posada y en plano más de gran público William Ospina y a nivel histórico Absalón Machado, para entender el poder de la tierra en el poder político colombiano.

MSEU: Como el movimiento de la historia es siempre contradictorio y conflictivo, a pesar de las adversidades enfrentadas en los campos de batalla que a menudo nos parecen a priori insuperables, siempre hay alguna esperanza de ganar «la guerra». En este sentido, ¿cuáles son las esperanzas que están movilizando a colombianos y colombianas para permanecer en la lucha?

Respuesta: La esperanza que tenemos al menos en mi caso, es grande, es multidimensional y multiescalar. Esta esperanza debe permanecer hasta que la dignidad se nos vuelva una costumbre. No obstante, respondo con tres ideas esperanzadoras puntuales que nos debe dejar este movimiento que comenzó en 2019, y continúa hoy en 2021 : 
$\checkmark$ Cualificar la opinión por medio de una escuela callejera de conocimiento: "La Primera Línea" es un buen ejemplo de ello

$\checkmark$ Lograr una equidad temporal: Que más allá de los gobiernos de turnos, los planes de desarrollo sean propuestas de políticas más allá de los 4 años de los gobernantes en el poder puntual para el que son elegidos

$\checkmark$ Producir y evidenciar un giro ontológico social: que aquellos que fueron los marginados, los silenciados, los borrados emerjan en liderazgos para ser escuchados y ponderados: indígenas con su trascendental idea de La Miga (trabajar juntos haciendo de la palabra acto); los afrocolombianos con su idea de La Juntanza (trabajar juntos), los barriales pobres marginados de las ciudades, los jóvenes reclamantes, las mujeres en sus distintos quehaceres, los maestros...

Béatriz Nates

UCALDAS

Manizales, 5 de junio de 2021 